\title{
(2)

\section{MODELO ADAPTADO DE PLANEJAMENTO ESTRATÉGICO APLICADO À MICROEMPRESAS: UM ESTUDO DE CASO NA ÁREA DE FITNESS}

\section{ADAPTED STRATEGIC PLANNIG MODEL APPLIED TO SMALL BUSINESS: A CASE STUDY IN THE FITNESS AREA}

\author{
Eduarda Tirelli Hennig* E-mail: eduardahennig@hotmail.com \\ Ângela de Moura Ferreira Danilevicz* E-mail: angelamfd@producao.ufrgs.br \\ Camila Costa Dutra* E-mail: camila@producao.ufrgs.br \\ *Universidade Federal do Rio Grande do Sul, UFRGS, Porto Alegre, RS
}

Resumo: O planejamento estratégico é uma ferramenta gerencial importante no cenário empresarial, não devendo restringir-se apenas a grandes empresas. Entretanto, a condução de um processo desse tipo de planejamento em micro e pequenas empresas pode necessitar de atividades adicionais em função de suas características próprias. Este trabalho tem como objetivo identificar e adaptar modelos de planejamento estratégico existentes para o cenário de uma microempresa. Inicialmente, realiza-se um estudo comparativo entre modelos de diversos autores com o fim de identificar suas fases e atividades para, então, definir quais delas devem estar presentes em um modelo a ser utilizado em microempresas. Tal modelo foi aplicado em um estúdio de Pilates e envolveu o estabelecimento de uma identidade organizacional, a realização de uma análise ambiental e a definição dos objetivos estratégicos, das estratégias e de ações para alcançá-los. Por fim, pôde-se identificar a geração de benefícios à organização e, também, as dificuldades encontradas na implantação da ferramenta.

Palavras-chave: Estratégia. Planejamento estratégico. Microempresa. Fitness. Estúdio de Pilates.

Abstract: The strategic planning is an important management tool in the corporate scenario and shall not be restricted to big Companies. However, this kind of planning process in small business may need special adaptations due to their own characteristics. This paper aims to identify and adapt the existent models of strategic planning to the scenario of a small business in the fitness area. Initially, it is accomplished a comparative study among models of different authors to identify theirs phases and activities. Then, it is defined which of these phases and activities should be present in a model that will be utilized in a small business. That model was applied to a Pilates studio; it involves the establishment of an organizational identity, an environmental analysis as well as the definition of strategic goals, strategies and actions to reach them. Finally, benefits to the organization could be identified, as well as hurdles in the implementation of the tool.

Keywords: Strategy. Strategic planning. Small business. Fitness. Pilates studio.

\section{INTRODUÇÃO}

No cenário mercadológico atual, observa-se uma constante mudança no ambiente político, social, econômico e cultural devido ao processo de globalização 
mundial. As organizações precisam ser suficientemente flexíveis para que respondam com rapidez a essas mudanças do mercado, sempre alinhadas a seus objetivos estratégicos. Segundo Porter (1996), é necessário que uma empresa tenha estratégias que lhe permitam desempenhar suas atividades de maneira diferente dos rivais ou, até mesmo, exercer atividades semelhantes de maneira diferenciada. Oliveira (1991) comenta que a sorte pode estar presente no bom desempenho da empresa, mas um produto a que muitas vezes se atribui a 'boa sorte' é fruto de uma boa estratégia. Entretanto, alguns empresários não possuem estratégias claramente delineadas em sua organização e conduzem suas ações de maneira intuitiva.

Atualmente, as microempresas são uma fonte importante para o desenvolvimento socioeconômico no Brasil. Há, no entanto, um grande índice de mortalidade ligado a esses empreendimentos (ROCHA, 2008). De acordo com o Serviço Brasileiro de Apoio às Micro e Pequenas Empresas - SEBRAE (2007), do universo de micro e pequenas empresas que são criadas a cada ano, 49,4\% fecham suas portas antes de completarem dois anos. As causas desse alto índice de mortalidade empresarial estão vinculadas a sua capacidade estratégica de responder às influências ambientais (SANTOS et al., 2007). De acordo com o SEBRAE, (2007), entre os fatores de sucesso das empresas empreendedoras estão o bom conhecimento do mercado em que atuam e as boas estratégias de vendas, e isso torna o planejamento estratégico importante para os microempresários.

Geralmente, o planejamento estratégico é visto como uma ferramenta formal e complexa cuja aplicação demanda tempo e dinheiro, sendo típico em grandes empresas; entretanto, seus benefícios podem ser usufruídos também por micro e pequenas empresas (SANTOS, 2005), substituindo a tendência dos empreendedores de não se engajarem em um planejamento formal e basearem suas estratégias em suas ações (KISFALVI, 2002). Brinckmann et al. (2010) afirmam que o planejamento aumenta a performance das pequenas empresas; todavia, seu desenvolvimento pode ser prejudicado se for informal, desestruturado, interativo e irregular. Desta maneira, o presente artigo tem como objetivo desenvolver um modelo adaptado de planejamento estratégico aplicado a microempresas, o qual é aplicado ao cenário de uma microempresa da área de fitness, mais especificamente um estúdio de Pilates. Para tal, fez-se necessária a identificação e adaptação de 
modelos existentes na literatura. O foco recai na hipótese de que o planejamento estratégico de uma micro ou pequena empresa não é, necessariamente, uma forma simplificada de se aplicarem as atividades nele previstas em médias e grandes empresas e pode, inclusive, necessitar de atividades específicas.

No cenário de estudo pode ser evidenciado, enquanto tendência, que profissionais recém-formados nos cursos de Educação Física e de Fisioterapia criam microempresas em função da dificuldade de encontrarem um emprego condizente com sua realização pessoal e financeira. Assim, estes profissionais acabam por atender em domicílio, abrir clínicas e estúdios ou prestar serviços através de firmas cooperativas (BORSATTO, 2006), mas ao se analisar o currículo desses cursos comprova-se que não existe disciplina alguma que prepare o aluno para a abertura de um negócio próprio. Como decorrência dessa lacuna, os profissionais que se formam no ramo da Educação Física e da Fisioterapia estão muito preparados tecnicamente para dar aulas e ajudar seus alunos e pacientes, e pouco preparados para gerir um negócio, não tendo, assim, a noção da real importância do planejamento estratégico para uma organização. Tais fatos mostram a relevância de uma sensibilização desses microempresários para a necessidade de avaliarem o ambiente competitivo e de definirem estratégias para o negócio.

A seguir, traz-se o referencial teórico sobre estratégia e planejamento estratégico. Posteriormente, descreve-se o método utilizado para, então, apresentar os resultados, descrevendo a empresa onde foi aplicado o estudo de caso, os benefícios obtidos e as dificuldades encontradas. Por fim, o artigo traz as conclusões obtidas da pesquisa.

\section{REFERENCIAL TEÓRICO}

Esta seção apresenta conceitos referentes à estratégia e ao planejamento estratégico. 


\subsection{Estratégia}

Antes de se elaborar um planejamento estratégico em uma empresa, é necessário ter uma definição clara de estratégia. Para Oliveira (1991), a estratégia está relacionada com uma adequada utilização dos recursos físicos, financeiros e humanos, a fim de ter as oportunidades maximizadas e os problemas minimizados. Segundo o autor, ao traçar uma estratégia deve-se perguntar sobre o destino que se quer dar à empresa e como se deve estabelecê-lo para um bom ajustamento dela em seu ambiente. É possível notar que o conceito de estratégia é bastante amplo. Mintzberg (2004) define estratégia em quatro diferentes enfoques:

- Plano: é uma direção para lidar com determinadas situações no futuro.

- Padrão: é um modelo do comportamento da empresa ao longo do tempo.

- Posição: é a definição de certos produtos e serviços em determinados mercados.

- Perspectiva: é a maneira como a empresa faz suas atividades de acordo com o conceito de seu negócio.

Santos et al. (2007) definem estratégia como um conjunto de padrões e comportamentos de uma empresa com o objetivo de alcançar uma vantagem competitiva. A empresa que apresenta uma vantagem competitiva sustentável é aquela que possui estratégias valiosas que não podem ser plenamente copiadas pelos concorrentes, o que resulta em retorno financeiro (WRIGHT et al., 2000). Segundo Thompson Jr. e Strickland III (2000), existem diversas fontes de vantagem competitiva, a exemplo de: ter o produto ou o serviço de melhor qualidade no mercado; estar em localização geográfica mais conveniente; ter reputação; e proporcionar aos clientes um maior valor pelo dinheiro.

A criação de estratégias vem sendo uma preocupação dos empresários desde a década de 50 , pois nessa época começou a surgir uma falta de sintonia entre a oferta de produtos e a absorção deles no mercado (ANSOFF; et al., 1990). A sustentação e o resultado de todo um desenvolvimento e da implantação de estratégias empresariais é o que se chama de planejamento estratégico (OLIVEIRA, 1991). 


\subsection{Planejamento Estratégico em micro e pequenas empresas}

O planejamento estratégico está vinculado às maneiras e às ações pelas quais uma empresa atingirá seus objetivos. Oliveira (1991) define planejamento estratégico como um processo gerencial que permite ao executivo da empresa estabelecer um rumo para ela a fim de otimizar a relação da empresa com seu ambiente.

Segundo Mintzberg (2004), um planejamento é fundamental para coordenar e controlar as atividades da empresa, assegurando que o futuro seja levado em consideração. Rasmussen (1990) afirma que o planejamento estratégico é importante, pois torna o processo decisório mais eficiente, estimulando 0 desenvolvimento e o crescimento da empresa no cumprimento dos objetivos estratégicos, facilitando e consolidando a integração de informações e fortalecendo o espírito de equipe. Além disso, o planejamento estratégico torna a empresa mais preparada para as mudanças (ROSSI; LUCE, 2002). Delmar e Shane (2003) asseguram, ainda, que com um planejamento os recursos são usados de modo mais eficiente, além de ele permitir uma atuação mais flexível frente ao mercado.

O tema formulação de estratégias por meio de um planejamento estratégico possui extensa bibliografia disponível. Autores como Certo e Peter (2005), Wright et al. (2000) e Haselhoff (1990) ampliam o conceito do planejamento estratégico considerando-o um processo contínuo e interativo chamado de administração estratégica. No entanto, todos os autores ressaltam a importância de definir, de alguma forma, a missão da empresa, analisar o ambiente em que ela se encontra, definir objetivos e desenvolver, implementar e controlar as estratégias, independentemente do nome atribuído a seus modelos.

Diferentes modelos de planejamento estratégico vêm sendo aplicados às empresas em geral, sendo alguns deles específicos para as pequenas empresas, mas acredita-se que esses modelos específicos sejam igualmente aplicáveis às microempresas. Ao avaliar as propostas de alguns modelos, pode-se verificar que não existe consenso entre as atividades a serem desenvolvidas, podendo variar em número e na ordem de sua execução. A Figura 1 contém modelos específicos, desenvolvidos especialmente para pequenas empresas, e modelos considerados de 
aplicação genérica, independente do tipo, do porte ou do produto da organização. Além disso, com base nos modelos analisados foi detalhada uma sequência de atividades possíveis de serem empregadas na realização do planejamento estratégico, iniciando-se pela apresentação da técnica e da conscientização do pequeno empresário, seguida do estabelecimento do negócio, do estabelecimento da missão, do estabelecimento da visão, e assim por diante. A seguir, com base nos modelos sugeridos pelos autores pesquisados, identificou-se a existência, ou não, dessas atividades e sua ordem de realização. Salienta-se que alguns autores englobam em um único título atividades que outros trouxeram de forma segmentada, a exemplo de Certo e Peter (2005), que intitulam de 'análise do ambiente' o conjunto de atividades que inclui: 1a) análise externa; 1b) análise das forças competitivas; e 1c) análise interna.

A partir da análise dos modelos de planejamento estratégico apresentados na Figura 1, pode-se observar que não existe uma única e certa maneira para sua realização, isso porque o foco do desenvolvimento do planejamento estratégico, dentro das organizações, pode estar, por exemplo, mais em uma fase do que em outra. Observa-se que os modelos mais detalhados são os de Oliveira (1991), Thompson Júnior e Strickland III (2000) e Fischmann e Almeida (1991) por contemplarem atividades que, muitas vezes, são consideradas desnecessárias por outros autores, a exemplo da proposta de Oliveira (1991), que sugere o estabelecimento de macroestratégias e de macropolíticas e o estabelecimento de políticas, e a de Fischmann e Almeida (1991), que sugerem inicialmente a preparação da organização para a implantação do planejamento estratégico, seguida da integração com o plano tático. Entretanto, existem atividades consideradas fundamentais e que são abordadas por todos os autores pesquisados, como definição da Missão, análise externa e interna, análise das forças competitivas e escolha da estratégia e dos objetivos. 
Figura 1 - Atividades sugeridas por diferentes autores em seus modelos

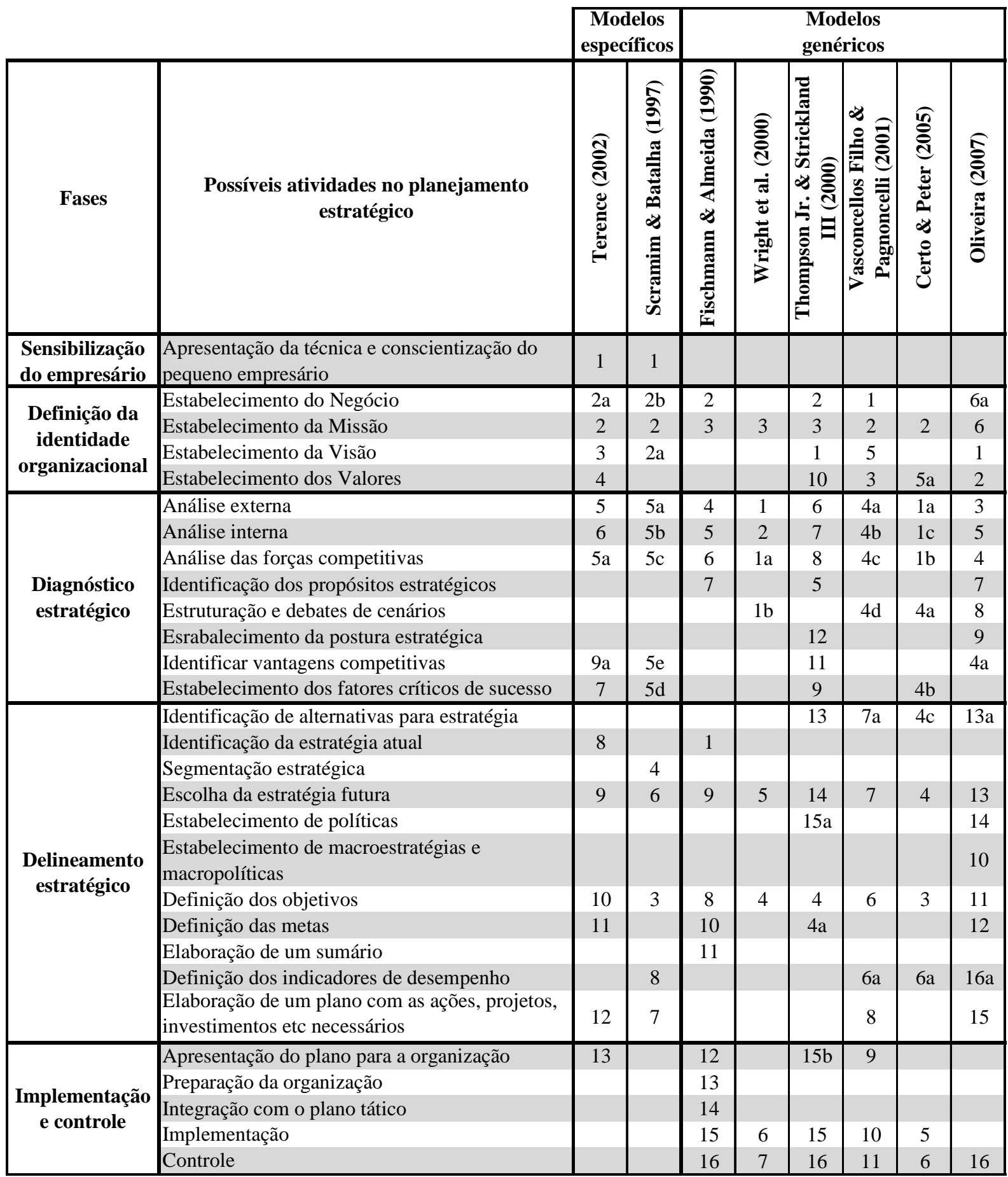

Fonte: Elaborado pelas autoras

Os modelos específicos para pequenas empresas, de Terence (2002) e Scramim e Batalha (1997), detalhados na Figura 1, basearam-se em modelos genéricos. Entre os motivos para essa adaptação está o fato de as pequenas empresas possuírem particularidades que deveriam ser consideradas. Terence 
(2002) afirma que dentre as principais dificuldades encontradas por pequenos empresários para a formulação de um planejamento estratégico estão a falta do conhecimento da ferramenta, a falta de pessoal qualificado, a falta de visão para longo prazo, o imediatismo associado a resultados, a dificuldade de aceitar mudanças e a dificuldade de analisar seu ambiente e definir sua identidade organizacional e suas estratégias. Piovezan et al. (2008) ainda acrescentam que alguns empresários têm dificuldade de explicitar a estratégia da empresa devido ao temor de que ela seja copiada pela concorrência, e que a base de dados obtida na análise do ambiente pode ser considerada fraca, uma vez que é baseada na experiência dos diretores e dos líderes da empresa.

Sendo assim, necessita-se, por exemplo, de uma primeira etapa de sensibilização dos empresários na qual se apresentará a definição de estratégia, sua função, seus benefícios e as atividades que estão envolvidas no planejamento estratégico. Além disso, ambos os modelos específicos para pequenas empresas trazem a necessidade da definição inicial da identidade organizacional, pois, antes de analisar o meio em que se encontram, essas empresas precisam definir de maneira clara quem são, o que fazem, o que valorizam e onde querem chegar.

A abordagem adotada nos modelos varia de um autor para outro. Vasconcellos Filho e Pagnoncelli (2001) desenvolveram um modelo com abordagem baseada em exemplos aplicados em diferentes mercados; já Fischmann e Almeida (1991) apresentaram uma abordagem em forma de história, a qual discorre sobre sua aplicação numa empresa familiar através da ajuda de um consultor. Há ainda aqueles que apresentam atividades a serem realizadas em grandes empresas, como Certo e Peter (2005), Thompson Júnior e Strickland III (2000) e Wright et al. (2000). Nessas obras, a abordagem adotada é mais ampla e discorre sobre a geração de estratégias em diferentes níveis organizacionais, como o empresarial, a unidade de negócio e o funcional. Além disso, Certo e Peter (2005) apresentam aplicações especiais da administração estratégica em negócios internacionais, e Wright et al. (2000), em organizações sem fins lucrativos.

Alguns autores utilizam ferramentas complementares durante a realização das atividades sugeridas. Para uma análise integrada dos ambientes internos e externos com a finalidade de identificar o posicionamento estratégico da empresa, 
Oliveira (2007) utiliza a Matriz SWOT (Strenghts - Forças; Weaknesses Fraquezas; Opportunities - Oportunidades; e Threats - Ameaças), em português, Análise FOFA. Outra ferramenta bastante utilizada é a Matriz ImportânciaDesempenho, de Slack et al. (2002), utilizada para a identificação dos fatores críticos de sucesso, isto é, fatores ganhadores de pedido, que devem ser diferenciados dos fatores competitivos, os quais não garantem pedidos, mas não os ter define que o pedido não está ganho. Assim, esta Matriz evidencia os objetivos ganhadores de pedidos, os qualificadores e os menos importantes.

Alguns exemplos de aplicação dos modelos genéricos disponíveis em micro e pequenas empresas encontram-se em Santos (2005), que aplicou o modelo de Certo e Peter (2005), e em Amaral (2004), que utilizou o modelo de Vasconcellos Filho e Pagnoncelli (2001).

\section{PROCEDIMENTOS METODOLÓGICOS}

Segundo Silva e Menezes (2001), este trabalho pode ser classificado, quanto a sua natureza, como uma pesquisa aplicada, pois é dirigido à solução de um problema específico. Para sua realização foi desenvolvida uma pesquisa exploratória que visa tornar o problema mais explícito, e foi utilizada uma abordagem qualitativa, pois o pesquisador não se baseia na utilização de instrumentos estatísticos para comprovar ou refutar as questões estudadas, mas, sim, de palavras para descrever o fenômeno. O procedimento utilizado foi o estudo de caso, o qual tem como finalidade a análise profunda de uma organização.

Ao desenvolver-se um planejamento estratégico, a divisão em fases e atividades torna o processo mais fácil de ser aplicado. Ao adaptar-se o modelo de planejamento estratégico, definindo as atividades a serem empregadas para microempresas, foram utilizados como base os modelos específicos de Terence (2002) e Scramim e Batalha (1997) e o modelo genérico de Thompson Jr. e Strickland III (2000). O modelo para microempresas adotado no presente trabalho encontra-se detalhado na Figura 2.

A Fase 1 consiste na realização de uma reunião presencial com os microempresários para o nivelamento dos conceitos e a identificação do 
conhecimento atual sobre estratégia e planejamento estratégico, para a posterior apresentação da ferramenta e sensibilização acerca de sua importância para a empresa. Como suporte a esta fase podem ser utilizados exemplos disponíveis na literatura, como os de Vasconcellos Filho e Pagnoncelli (2001), além de checklist contendo os conceitos a serem tratados na reunião.

Na Fase 2 é definida a identidade organizacional, a qual envolve o estabelecimento do Negócio, da Missão, da Visão e dos Valores. Nessa fase buscase identificar, por meio de reuniões com os microempresários, o que a empresa é, o que faz, aonde quer chegar e o que valoriza. Pode-se realizar uma dinâmica com questionamentos que auxiliarão as definições. Por exemplo: 'Qual é o seu negócio?', 'Quem é seu cliente?', 'O que é importante para as partes interessadas?'.

Figura 2 - Modelo de planejamento estratégico para microempresas

Fase 1: Nivelamento de conceitos e sensibilização para o Planejamento Estratégico

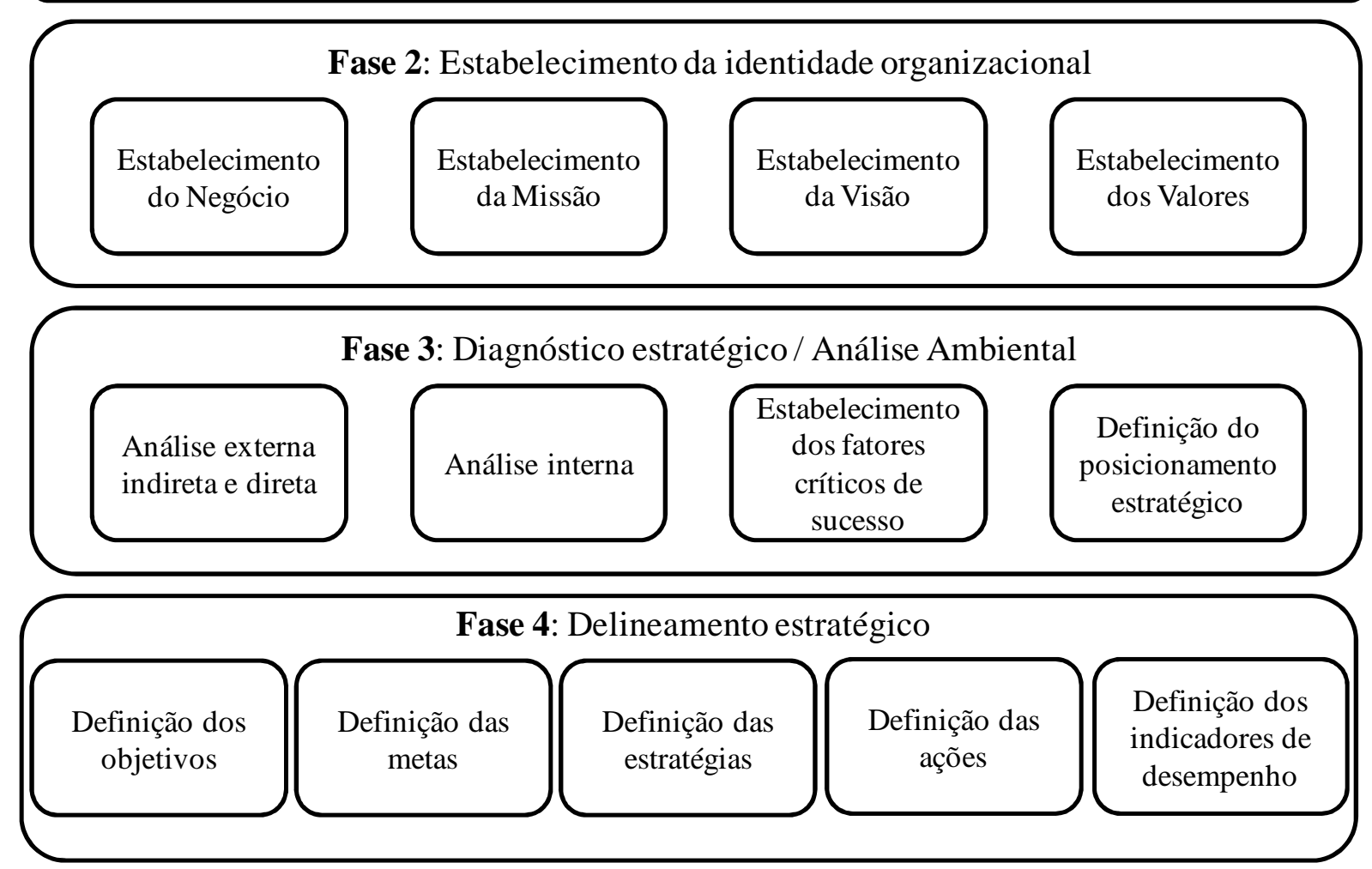

Fonte: Elaborado pelas autoras

A Fase 3 constitui-se do diagnóstico estratégico, desdobrado na análise dos ambientes externo (indireto e direto) e interno; além disso, são estabelecidos os 
fatores críticos de sucesso e o posicionamento estratégico. Todas essas atividades contemplam a realização de reuniões presenciais com os microempresários. Na análise externa indireta avalia-se o grau de influência dos fatores econômicos, socioculturais, políticos e tecnológicos. Posteriormente, realiza-se a análise externa direta, através das cinco forças competitivas de Porter (2004): ameaças dos novos entrantes, poder de barganha dos clientes, poder de barganha dos fornecedores, ameaça dos produtos substitutos e rivalidade dos concorrentes existentes. Esta análise possibilita que se determine quais são as oportunidades e as ameaças à empresa. A seguir, realiza-se a análise interna, na qual são definidos os pontos fortes e fracos em relação aos recursos da empresa. Rasmussen (1990) e Mintzberg et al. (2000) sugerem que essa análise seja segmentada em áreas ou funções como: financeira, recursos humanos e marketing.

Nesta fase também são estabelecidos os fatores críticos de sucesso (ganhadores de pedido) que, segundo Slack et al. (2002), auxiliam a análise da relação cliente - empresa - concorrente. Tais fatores são analisados através da Matriz de Importância-Desempenho, na qual eles podem ser classificados em quatro grupos distintos: 'zona de excesso', 'zona apropriada', 'zona de melhoramento' e 'zona de ação urgente'. A cada fator competitivo é atribuída uma pontuação relacionada ao desempenho frente aos concorrentes e outra em relação à importância dada pelos clientes. Para isto, utilizam-se escalas discretas de 9 pontos. Na avaliação do desempenho, atribui-se o valor de: 1 a 3 pontos para desempenho melhor que os concorrentes; 4 a 6 pontos para desempenho similar ao dos concorrentes; 7 a 9 pontos para desempenho pior do que o dos concorrentes. Para a avaliação da importância dada pelos clientes atribuem-se: 1 a 3 pontos para fator ganhador de pedidos; 4 a 6 pontos para fator que torna a empresa qualificada; 7 a 9 pontos para fator pouco importante ao cliente (SLACK; et al., 2002).

A partir disso, aplica-se a Matriz SWOT para analisar a posicionamento estratégico da empresa, quando são atribuídos pesos de importância aos pontos fortes e fracos, às oportunidades e às ameaças, para a posterior identificação do posicionamento estratégico a ser adotado. A escala de importância adotada, segundo Müller (2003), é a seguinte: peso 3 para importância baixa, peso 6 para importância intermediária e peso 9 para importância elevada. Cruzam-se as 
oportunidades e as ameaças com os pontos fortes e fracos, identificando possíveis relações entre eles. Nas interseções existentes é anotada a multiplicação dos pesos atribuídos aos respectivos itens. No final, somam-se os valores constantes em cada quadrante correspondente aos posicionamentos estratégicos que a empresa pode adotar: quadrante 'desenvolvimento' (cruzamento entre Pontos Fortes $x$ Oportunidades); quadrante 'crescimento' (cruzamento entre Pontos Fracos $x$ Oportunidades); quadrante 'manutenção' (cruzamento entre Pontos Fortes $x$ Ameaças); e quadrante sobrevivência (cruzamento entre Pontos Fracos x Ameaças). A Figura 3 apresenta um exemplo esquemático dessa Matriz.

A Fase 4, delineamento estratégico, estabelece os objetivos, as metas e as estratégias da empresa. Outra atividade importante é o estabelecimento das ações a serem desempenhadas a fim de alcançar os objetivos. Posteriormente, devem-se estabelecer os indicadores de desempenho para o controle do cumprimento das estratégias. Essas atividades demandam encontros presenciais com os microempresários, nos quais se podem utilizar recursos multimídia para a construção de quadro resumo, que contém objetivos e metas desdobrados em estratégias que, por sua vez, são desdobradas em ações. Um exemplo deste quadro será apresentado na seção 4.

É recomendado que a cada novo encontro se relembre o que foi definido nas reuniões anteriores, além da apresentação dos conceitos a serem tratados no dia. $A$ seguir, mostra-se a aplicação prática do método descrito. 
Figura 3 - Exemplo de quantificação das relações existentes na Matriz SWOT

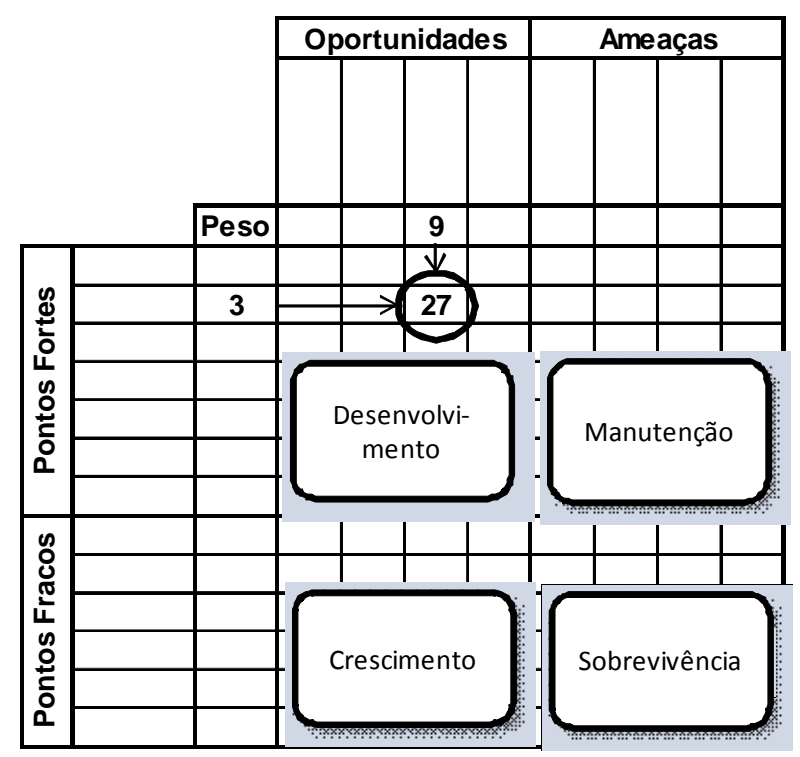

Fonte: Adaptado de Müller (2003)

\section{APLICAÇÃO DO MODELO DE PLANEJAMENTO ESTRATÉGICO ADAPTADO}

A presente seção apresenta, inicialmente, a empresa foco e, em seguida, a aplicação do modelo de planejamento estratégico adaptado. Por fim, são descritos os benefícios obtidos e as dificuldades encontradas a partir de tal aplicação.

\subsection{A Empresa}

A organização foco do planejamento estratégico é uma microempresa que atua no ramo de fitness, mais especificamente em aulas de Pilates. O Método Pilates, que desenvolve o condicionamento físico e mental e é mundialmente difundido, foi desenvolvido pelo alemão Joseph Hubertus Pilates no início da década de 1920, fazendo uso de equipamentos e acessórios como bolas, rolos e aparelhos com sistemas de molas (HAETINGER, 2009).

A empresa possui duas sedes, sendo que a matriz, no bairro Bela Vista, em Porto Alegre/RS, foi fundada em 2006, e a filial, com participação societária de outro sócio, foi fundada em março de 2009 na cidade de Gramado/RS. Em nenhuma delas há funcionários contratados. A sede no bairro Bela Vista conta com mais de 40 
alunos, com idade de 18 a 80 anos, e suas aulas são ministradas pelo proprietáriofundador.

Atualmente, a gestão estratégica da empresa concentra-se no sócio fundador, não havendo um planejamento estratégico formal. Além disso, é o sócio fundador quem controla toda a parte comercial e financeira da empresa, possuindo apenas um contador terceirizado para auxiliá-lo. Entretanto, existe forte interesse por parte dos sócios para a realização do plano estratégico, a fim de obterem uma estrutura mais organizada, tendo em vista o crescimento da empresa.

\subsection{Resultados da aplicação}

A aplicação do modelo na empresa em estudo foi desenvolvida ao longo de três meses, nos quais foram realizadas oito reuniões com os sócios, com duração aproximada de duas horas cada uma. Na Fase 1, primeiramente procurou-se identificar o conhecimento dos empresários sobre estratégia e planejamento estratégico, a fim de integrar sua percepção com os conceitos encontrados na literatura. Posteriormente, foram apresentadas as vantagens da implantação de tal ferramenta em uma microempresa, bem como o modelo de planejamento estratégico proposto neste artigo, explicando o que seria realizado em cada fase.

A Fase 2, identidade organizacional, contribuiu para formalizar os conceitos que a empresa tinha sobre quem ela é, onde quer chegar e o que valoriza. Para isso, utilizaram-se exemplos de identidades organizacionais de outras empresas do setor encontrados em Vasconcellos Filho e Pagnoncelli (2001). Primeiramente, estruturou-se um rascunho com a declaração do Negócio, da Missão, da Visão e dos Valores da empresa, tendo em vista que a empresa considera a qualidade em seu atendimento como o diferencial competitivo. Num segundo momento, o rascunho foi revisado e consolidado, realizando-se, então, a redação final dos conceitos.

Como resultado, obteve-se como definição de Negócio da empresa o ramo da saúde e bem-estar. A Missão da empresa foi definida da seguinte maneira: "Utilizar o Método Pilates como meio de promoção de saúde, bem-estar físico e mental e qualidade de vida para a sociedade, através de profissionais capacitados em um ambiente agradável". Com relação à Visão, a empresa estabeleceu que quer ter sua 
marca conhecida regionalmente por seus serviços prestados. Por fim, os empresários definiram seus Valores: ética, segurança, honestidade, busca pela excelência no atendimento, busca permanente do aperfeiçoamento, dedicação em tudo o que faz, organização e pontualidade.

A Fase 3 dividiu-se em três etapas, uma para a análise externa, uma para a análise interna e outra para a realização das matrizes Importância-Desempenho e SWOT. Na análise externa indireta buscou-se, inicialmente, levantar as tendências socioculturais, econômicas, políticas e tecnológicas que podem proporcionar oportunidades e ameaças à empresa.

Com relação ao aspecto sociocultural, foi evidenciada sua especial influência na empresa. A razão para isso deriva da crescente preocupação com a saúde e a beleza do corpo por parte da população, devido ao aumento de fatores como estresse e sedentarismo, além do aumento da perspectiva de vida, entre outros, os quais levam as pessoas a buscar os benefícios proporcionados pela atividade física para uma melhora em sua qualidade de vida. Além disso, percebeu-se que a mídia influencia diretamente na conscientização acerca da importância da realização de atividades físicas, por meio da divulgação de seus benefícios, principalmente na prevenção de doenças.

Os fatores econômicos influenciam a empresa na medida em que o mercado das atividades esportivas está aquecido, crescendo fortemente, e por isso vêm sendo criadas muitas novas modalidades. Verificou-se também que uma crise econômica pode influenciar, de certa forma, o negócio, já que alguns clientes podem deixar de realizar as aulas por as considerarem uma atividade supérflua. Entretanto, ressalta-se que a empresa considera que tais efeitos são minimizados pelo fato de seus clientes serem bastante fiéis e com renda estável.

Já os fatores políticos têm influência apenas quando o Governo adota medidas como aumento de impostos. Além disso, concluiu-se que os efeitos sobre o negócio seriam pequenos, já que a margem de lucro não é tão justa, e afetaria igualmente os concorrentes.

Ainda na análise externa, verificou-se que os fatores tecnológicos podem proporcionar oportunidades, já que, com a virtualização mundial, boa parte da população tem estado diariamente conectada à Internet, muitas vezes utilizando 
sites de busca, os quais podem se tornar uma ferramenta aliada ao marketing da empresa, por exemplo, pela possibilidade de seu site aparecer entre os primeiros endereços listados.

Os resultados obtidos na análise do ambiente externo direto apresentam as forças competitivas que influenciam as atividades da empresa. A primeira força competitiva descrita foi o poder de barganha dos clientes. Primeiramente, definiu-se que os clientes são todas as pessoas acima de 15 anos de idade, com poder aquisitivo, conscientes de que o Método Pilates proporciona benefícios físicos e mentais, como flexibilidade, fortalecimento muscular, melhora da postura, alívio de estresse, de dores e de tensões crônicas. Muitos deles são moradores das regiões onde estão localizados os estúdios. Tais clientes acabam tendo poder de barganha quando passam a ser fiéis à atividade, pois, quanto maior for o tempo de vínculo com a empresa, maior será seu poder de pedir descontos. Uma situação que deve ser ressaltada é que alguns clientes em potencial acabam optando por empresas concorrentes mais baratas e com qualidade inferior, tendo em vista o pouco conhecimento do método para avaliar o custo versus a qualidade ao seu dispor. Além disso, devido à importância da atividade aeróbica, muitos clientes acabam realizando outro exercício físico, além do Pilates, ou optam por apenas realizar outra atividade, por falta de condições financeiras.

Com relação à concorrência, é possível afirmar que ela é composta por todos os estúdios e academias que ministram aulas de Pilates. Entre os concorrentes mais fortes da matriz estão os três mais antigos da cidade e os dois fraqueados de uma empresa nacionalmente conhecida.

Com relação aos fornecedores, há basicamente duas categorias: o de equipamentos e o locatário. Há em torno de dez fornecedores de equipamentos que detêm mais de $90 \%$ do mercado nacional, cujos preços e qualidade possuem grande diversidade e permitem uma boa margem para a negociação de preços; já os espaços estão sujeitos aos preços e às disponibilidades do mercado imobiliário que, em geral, também são bastante variados.

Os produtos substitutos englobam toda e qualquer atividade física, desde aquelas sem custo algum, praticadas em casa ou na rua, até as mais caras, personalizadas ao aluno. 
Por fim, com relação à última força competitiva, pode-se dizer que praticamente inexistem barreiras aos novos entrantes, os quais estão se multiplicando no mercado.

$\mathrm{Na}$ análise do ambiente interno da empresa foram escolhidas, tendo em vista o ramo empresarial, as seguintes funções cujos pontos fortes e fracos devem ser auditados: serviços prestados, questões financeiras, recursos humanos, marketing e instalações e equipamentos.

O serviço prestado pela empresa é extremamente personalizado e padronizado. As aulas são consideradas de qualidade, a partir de um feedback por parte dos alunos e da imagem e reputação da empresa. Entretanto, a empresa não apresenta grande participação do mercado, já que este é bastante segmentado. A empresa também não possui um indicador formal da qualidade de seus serviços, mas controla seu desempenho pela fidelidade dos alunos. A capacidade ociosa da matriz é muito baixa; sendo assim, praticamente inexistem horários disponíveis para novos alunos, apesar da grande diversidade de horários oferecidos, de segunda a sexta-feira, das 7 às 22 horas; já a filial apresenta uma capacidade ociosa maior, com grande possibilidade de captação de novos alunos. A empresa não possui um monitoramento formal da evolução do aluno, apenas subjetivo.

Com relação à função financeira, é possível afirmar que o faturamento da empresa vem crescendo com certa rapidez e, mesmo em períodos de recessão econômica, apresentou ganhos estáveis. A empresa não possui problemas relacionados com inadimplência por parte dos alunos. A maior parte de seus custos são fixos, incluindo aluguel, domínio e provedor do site e contador, entre outros. O controle desses gastos não é realizado de maneira adequada e não há uma separação das contas pessoais dos sócios e da empresa, enquanto o controle de receitas possui um maior detalhamento. Mesmo assim, não há um controle de indicadores de desempenho adequado.

Tendo em vista as instalações, observa-se que elas apresentam um ambiente agradável, limpo e climatizado; já com relação aos equipamentos, estes são todos novos e apresentam-se em boas condições de uso. Há uma variedade de aparelhos, apesar de não contarem com aparelhos repetidos. Não há espaço para expansão das atuais instalações. Ambas as sedes possuem armários para artigos pessoais, e 
uma delas oferece vestiários com chuveiros e bebedores. A empresa também oferece estacionamento para seus alunos.

Em relação ao marketing da empresa, é possível afirmar que sua divulgação é realizada, basicamente, por meio de indicações. Além disso, a empresa desenvolveu um site institucional, sendo o primeiro a aparecer em sites de busca, o qual é um diferencial em relação aos concorrentes, que muitas vezes não utilizam essa ferramenta.

Por fim, analisando os recursos humanos da empresa, concluiu-se que os professores são considerados de ótima qualidade, demonstrando interesse e preocupação com o aluno. Eles são pontuais e possuem um bom treinamento; entretanto, a experiência profissional do professor da filial é menor. A remuneração é considerada boa e motivadora. Há poucos recursos humanos para dedicação às questões gerenciais, em detrimento das questões operacionais.

A partir das informações obtidas anteriormente foi possível levantar os fatores competitivos da empresa, que foram classificados conforme a importância para os clientes e o desempenho em relação aos concorrentes, apresentado na Figura 4.

Vê-se na Figura 4 que a maioria dos fatores competitivos da empresa se encontram na 'zona apropriada', com exceção de experiência e imagem e reputação, que estão posicionados da 'zona de melhoramento'. Pode-se dizer que a empresa possuiu um nível intermediário de experiência em relação ao segmento, já que foi fundada em 2006, enquanto alguns poucos concorrentes já vêm ministrando aulas de Pilates desde 1997, e outros abriram suas empresas nesse mesmo período ou depois. Além disso, sua imagem e reputação são boas em relação às da maioria dos concorrentes. Entretanto, as franqueadas vêm entrando do mercado com uma marca mais forte e antiga. 
Figura 4 - Matriz: Importância-Desempenho
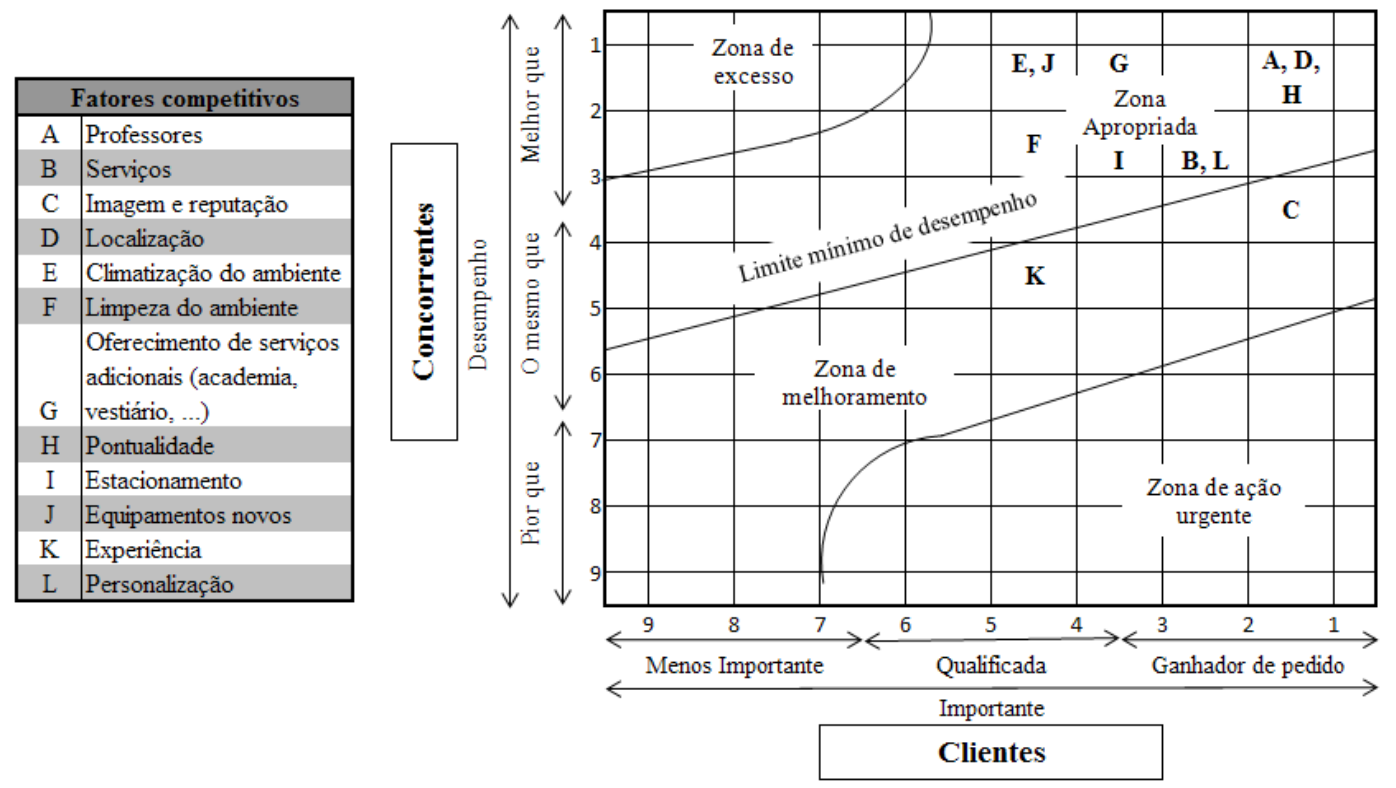

Fonte: Adaptado de Slack et al. (2002)

A relação obtida entre os pontos fortes e fracos da empresa com as oportunidades e as ameaças foi realizada através da construção da Matriz SWOT, representada na Figura 5. Analisando a Matriz da Figura 5, percebe-se que a empresa possuiu maior pontuação no quadrante referente ao cruzamento de pontos fortes e oportunidades - o quadrante 'Desenvolvimento' totaliza 936 pontos, contra 288, 396 e 144 nos quadrantes 'Manutenção', 'Crescimento' e 'Sobrevivência', respectivamente - o que demonstra que a empresa possui um posicionamento estratégico de desenvolvimento de mercado. Entretanto, muitos pontos fracos da empresa devem ser superados e utilizados para aproveitar as oportunidades do mercado; caso contrário, poderá haver o fortalecimento de concorrentes e de produtos substitutos. Além disso, alguns pontos fortes, como imagem, reputação, rentabilidade e fidelidade dos clientes, podem ser abalados devido à existência da ameaça de crescimento ou fortalecimento de concorrentes e produtos substitutos. 
Figura 5 - Matriz SWOT

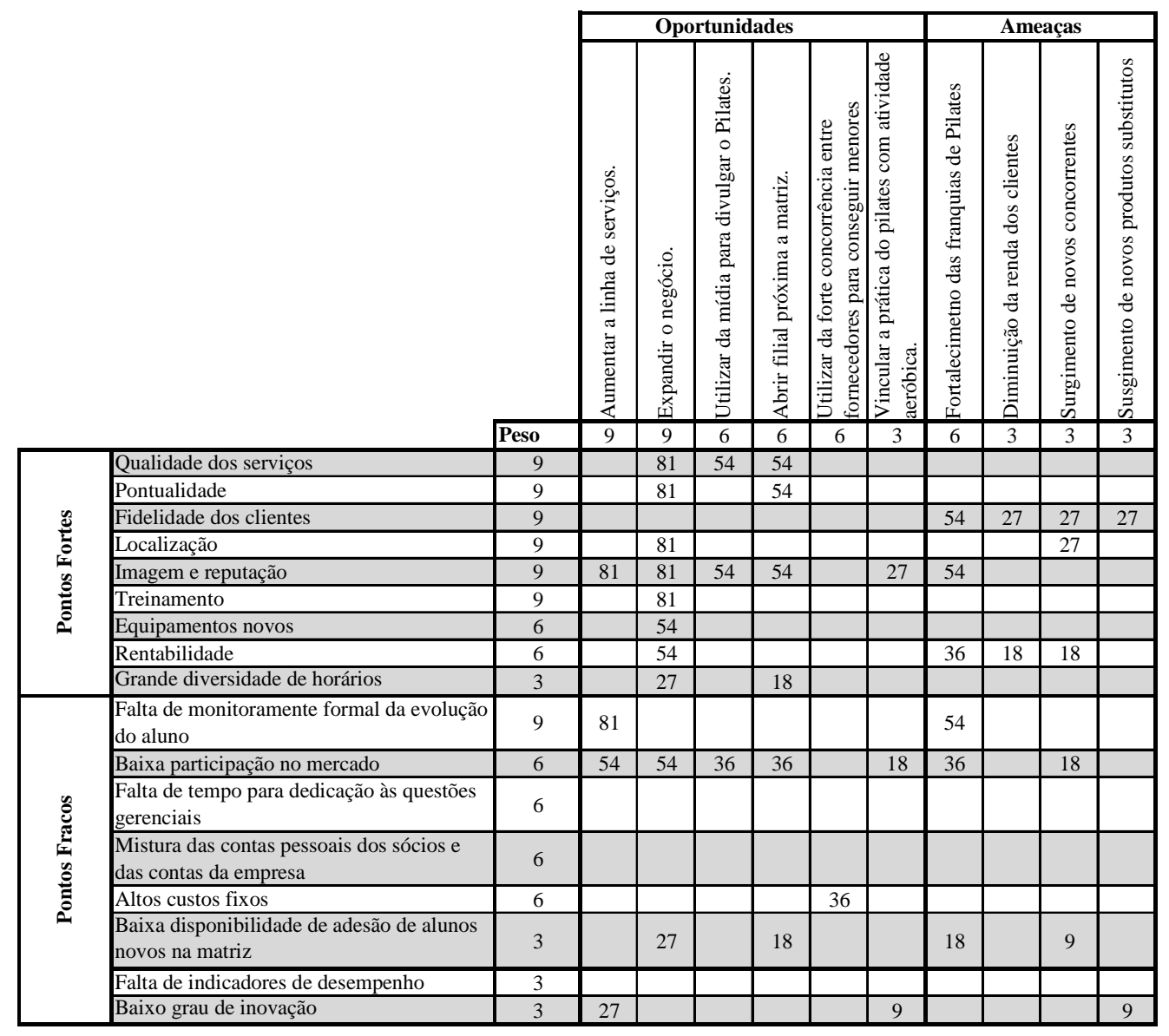

Por fim, a Fase 4 foi realizada em dois momentos: o primeiro para a definição de objetivos e metas, e o segundo para a elaboração das estratégias, ações e indicadores de desempenho. Seu resultado pode ser observado na Figura 6. Cabe ressaltar que o planejamento realizado prevê ações de curto, de médio e de longo prazo.

Ao analisar os objetivos da Figura 6 com mais profundidade, percebe-se que todos estão relacionados com o fim de alcançar um objetivo maior: o crescimento da empresa. Assim, todas as estratégias foram criadas com a finalidade de desenvolver uma estrutura base para sustentar sua expansão no mercado. Já os indicadores de desempenho foram desenvolvidos para verificar se os resultados esperados da implantação das estratégias estarão sendo atingidos, principalmente em relação a cada estabelecimento. Para isso, as seguintes informações serão motivo de acompanhamento pelos gestores, os quais irão calcular por sede: o número de alunos, o número de horas de aula vendidas, a receita bruta, a receita líquida e os gastos, além do número de horas de treinamento dos professores por ano.

Revista Produção Online, Florianópolis, SC, v.12, n. 2, p. 270-296, abr./jun. 2012. 
Figura 6 - Objetivos, Metas, Estratégias e Ações

\begin{tabular}{|c|c|c|}
\hline Objetivos e Metas & Estratégias & Ações \\
\hline \multirow[t]{2}{*}{$\begin{array}{l}\text { Objetivo: } \\
\text { - Crescer. } \\
\text { Meta: } \\
\text { - Abrir uma filial por } \\
\text { semestre nos próximos } \\
\text { três anos. }\end{array}$} & $\begin{array}{l}\text { - Desenvolver parcerias } \\
\text { para a abertura de novas } \\
\text { filiais. } \\
\text { - Estruturar uma base } \\
\text { gerencial para o } \\
\text { crescimento. } \\
\end{array}$ & $\begin{array}{l}\text { - Pesquisar locais potenciais para a } \\
\text { abertura de novas filiais. } \\
\text { - Instalar câmeras de vídeo para o } \\
\text { controle das filiais. } \\
\text { - Desenvolver software para o } \\
\text { controle unificado das filiais. } \\
\end{array}$ \\
\hline & $\begin{array}{l}\text { - Elaborar uma política de } \\
\text { preços. }\end{array}$ & $\begin{array}{l}\text { - Oferecer pacotes de aulas mensais } \\
\text { (uma, duas ou três vezes por } \\
\text { semana) e cobrar a mais dos alunos } \\
\text { que trocarem de horário. } \\
\text { - Oferecer preço mais baixo por aula } \\
\text { quanto mais vezes na semana. } \\
\end{array}$ \\
\hline \multirow{2}{*}{$\begin{array}{l}\text { Objetivo: } \\
\text { - Diversificar produtos e } \\
\text { serviços. } \\
\text { Metas: } \\
\text { - Formalizar a oferta de } \\
\text { serviço de consultoria até } \\
2014 \text {. } \\
\text { - Criar curso de formação } \\
\text { de profissionais de } \\
\text { Pilates até } 2011 \text {. }\end{array}$} & $\begin{array}{l}\text { - Estruturar o serviço de } \\
\text { consultoria. }\end{array}$ & $\begin{array}{l}\text { - Planejar o serviço. } \\
\text { - Divulgar o serviço. }\end{array}$ \\
\hline & $\begin{array}{l}\text { - Estruturar curso de } \\
\text { formação de profissionais } \\
\text { de Pilates. }\end{array}$ & $\begin{array}{l}\text { - Fazer a apostila para o curso. } \\
\text { - Definir espaço para a realização do } \\
\text { curso. } \\
\text { - Divulgar o curso. } \\
\text { - Captar alunos. }\end{array}$ \\
\hline $\begin{array}{l}\text { Objetivo: } \\
\text { - Desenvolver equipe de } \\
\text { professores altamente } \\
\text { qualificados. } \\
\text { Meta: } \\
\text { - Ter todos os } \\
\text { professores com um } \\
\text { treinamento mínimo de } \\
60 \text { horas/aula em Pilates. } \\
\text { - Ter todos os } \\
\text { professores participando } \\
\text { de, no mínimo, um } \\
\text { workshop por ano (8 -12 } \\
\text { horas). }\end{array}$ & $\begin{array}{l}\text { - Fornecer treinamento } \\
\text { contínuo. } \\
\text { - Estimular os professores } \\
\text { para que realizem cursos } \\
\text { extras de aperfeiçoamento. }\end{array}$ & $\begin{array}{l}\text { - Realizar capacitação mínima de } 20 \\
\text { horas com cada professor novo. } \\
\\
\text { - Realizar uma reunião mensal de } 2 \\
\text { horas com os professores para } \\
\text { acompanhamento, discussão de } \\
\text { casos especiais e exercícios novos. }\end{array}$ \\
\hline $\begin{array}{l}\text { Objetivo: } \\
\text { - Proporcionar um } \\
\text { espaço físico motivador. } \\
\text { Meta: } \\
\text { - Fazer alterações no } \\
\text { ambiente físico e nos } \\
\text { equipamentos no mínimo } \\
\text { a cada dois anos. } \\
\end{array}$ & $\begin{array}{l}\text { - Renovação do espaço } \\
\text { - Renovação de } \\
\text { equipamentos }\end{array}$ & $\begin{array}{l}\text { - Planejar e executar alterações no } \\
\text { espaço físico bianualmente. } \\
\text { - Trocar equipamentos a cada três a } \\
\text { cinco anos. } \\
\text { - Trocar molas dos equipamentos a } \\
\text { cada dois anos. }\end{array}$ \\
\hline $\begin{array}{l}\text { Objetivo: } \\
\text { - Ter uma imagem forte e } \\
\text { reconhecida. }\end{array}$ & $\begin{array}{l}\text { - Divulgar uma imagem } \\
\text { positiva da empresa. } \\
\text { - Atingir um número maior } \\
\text { de profissionais da área } \\
\text { através de consultoria e } \\
\text { curso de formação. } \\
\text { - Crescer. } \\
\text { - Fidelizar os clientes. }\end{array}$ & $\begin{array}{l}\text { - Oferecer brindes aos alunos em } \\
\text { datas festivas. } \\
\text { - Mandar mensagens de aniversário. } \\
\text { - Planejar anualmente o folder da } \\
\text { empresa. } \\
\text { - Manter o site atualizado. } \\
\text { - Participar de eventos relacionados } \\
\text { com o esporte para a divulgação da } \\
\text { marca. }\end{array}$ \\
\hline
\end{tabular}

Revista Produção Online, Florianópolis, SC, v.12, n. 2, p. 270-296, abr./jun. 2012. 
Cabe salientar que os indicadores de desempenho sugeridos são de simples gerenciamento e serão acompanhados por sede, uma vez que são negócios que seguem uma mesma estratégia e filosofia, mas que são quase independentes, já que cada filial da empresa é constituída por diferentes sócios. Essa é uma forma de manter controle direto sobre o sucesso de cada sede e permitir, posteriormente, a compilação de indicadores globais do negócio.

\subsection{Benefícios obtidos e dificuldades encontradas a partir da aplicação do modelo}

Oriundos da aplicação do planejamento estratégico na empresa em estudo, podem ser evidenciados benefícios associados à organização e às dificuldades vivenciadas durante a aplicação. Entre os benefícios que a ferramenta proporcionou ao estúdio de Pilates estão: o conhecimento da política de preços dos concorrentes para a estruturação da sua forma de precificação e a percepção da necessidade de ações que nunca antes haviam sido pensadas para 0 desenvolvimento organizacional. Além disso, foram definidas estratégias interligadas, visando ao objetivo maior da empresa: o crescimento.

Durante o desenvolvimento do planejamento estratégico foram enfrentadas certas dificuldades relacionadas à falta de familiaridade do empreendedor com a ferramenta. Primeiramente, pôde-se observar que os empreendedores não conseguiam separar as qualidades que a empresa realmente tinha daquelas que eles gostariam que tivesse. Outra dificuldade encontrada está associada à elaboração das estratégias, quando se deveria selecionar não só os caminhos a serem percorridos, como também aqueles que não seriam seguidos. Houve forte tendência à diversificação do negócio com aulas, consultoria e cursos, pois, no curto prazo, essas atividades extras trazem aumento à receita. Dessa forma, percebeu-se que os empresários tinham dificuldade para manter o foco em um serviço principal.

No processo de elaboração das estratégias também foram enfrentados problemas associados à utilização dos conceitos abstratos, principalmente com a distinção e o relacionamento entre estratégias e objetivos. E ainda, surgiram dificuldades na definição de um planejamento para o longo prazo, uma vez que a visão dos empreendedores é de curto prazo. 
Além disso, pôde-se verificar que os empresários ainda não davam o devido valor à ferramenta, mesmo após a atividade de sensibilização para o planejamento estratégico. Existia uma tendência, por parte dos empreendedores, de não priorizar tempo e dinheiro para a realização das atividades estratégicas (de planejamento), em detrimento das atividades operacionais.

\section{CONSIDERAÇÕES FINAIS}

No cenário atual de competição acirrada e globalização, a geração de estratégias contribui com a organização no sentido de dar um norte a suas ações, além de contribuir em seu processo de tomada de decisão. Assim, de maneira a atender seu objetivo principal, o presente trabalho desenvolveu, com base no referencial teórico apresentado, um modelo adaptado de planejamento estratégico associado a microempresas, identificando a necessidade de etapas especiais para a aplicação dessa ferramenta em tal segmento.

O modelo desenvolvido é composto por quatro fases: (i) nivelamento de conceitos e sensibilização para o planejamento estratégico; (ii) estabelecimento da identidade organizacional; (iii) diagnóstico estratégico; e (iv) delineamento estratégico. Cada fase foi desdobrada em atividades específicas. A aplicação do modelo deu-se em uma empresa do ramo de fitness, mais especificamente em um estúdio de Pilates, e contribuiu para a estruturação de sua forma de precificação, para o planejamento de ações que contribuam para seu desenvolvimento organizacional e para a definição de estratégias interligadas com foco no crescimento da empresa.

Fazer um estudo em uma única empresa não é conclusivo quanto à validade geral do modelo. Sendo assim, mais casos devem ser desenvolvidos para a validação. Esses estudos também devem verificar se, no longo prazo, a atividade de planejar estrategicamente foi absorvida na cultura da empresa, trazendo resultados adequados para ela.

Como aspectos positivos do modelo, pode-se afirmar que houve um aumento do conhecimento do ambiente competitivo, da percepção da necessidade de novas 
ações e do desenvolvimento de estratégias alinhadas com o objetivo maior da empresa, que é seu crescimento.

Por outro lado, como pontos negativos encontraram-se dificuldades relacionadas à falta de familiaridade com a ferramenta, problemas em distinguir como a empresa realmente é de como os empresários gostariam que ela fosse, falta de foco para a definição de estratégias, problemas na utilização de conceitos abstratos relacionados às questões estratégicas, falta de visão para o longo prazo e pouca disponibilização de tempo e dinheiro para a condução das atividades. Cabe ressaltar que as dificuldades aqui relatadas são muito similares àquelas apresentadas por Terence (2002) para a realização de planejamento estratégico em pequenas empresas.

Algumas dessas dificuldades poderiam ter seus efeitos minimizados se esses profissionais de Educação Física e Fisioterapia possuíssem, durante seu período de formação, alguma disciplina de Administração que apresentasse conceitos a respeito de gestão e de planejamento estratégico, tendo em vista que esses microempresários já os teriam assimilado.

Em virtude dos resultados obtidos, é importante evidenciar que a aplicação do planejamento estratégico em uma microempresa contribuiu para o processo de 'parar para pensar' estrategicamente. Sendo assim, considera-se relevante a disseminação e a aplicação desta ferramenta para pequenas e micro empresas, como forma de perenizar o negócio.

\section{REFERÊNCIAS}

AMARAL, Cláudio Cirino Nunes do. O planejamento estratégico para uma instituição de contabilidade: um estudo de caso. 2004. Trabalho de conclusão (Mestrado em Engenharia de Produção) - Universidade Federal do Rio Grande do Sul. Porto Alegre, 2004.

ANSOFF, Igor H.; DECLERCK, Roger P.; HAYES, Robert L. Do planejamento estratégico à administração estratégica. In: Do planejamento

estratégico à administração estratégica. São Paulo: Atlas, 1990. 271p. parte 2, p.48-90.

BORSATTO, Vera Lúcia. Empreendedorismo em fisioterapia: a visão e o planejamento de um negócio empreendedor. 2006. Tese. (Mestrado 
Profissionalizante em Administração) - Faculdade de Economia e Finanças IBMEC. Rio de Janeiro, 2006.

BRINCKMANN, Jan; GRICHNIK, Dietmar; KAPSA, Diana. Should entrepreneurs plan or just storm the castle? A meta-analysis on contextual factors impacting the business planning-performance relationship in small firms. Journal of Business Venturing, v.25, p.24-40, 2010.

CERTO, Samuel C.; PETER, J. Paul. Administração estratégica: planejamento e implantação da estratégia. 2.ed. São Paulo: Makron Books, 2005.

DELMAR, Frédéric. SHANE, Scott. Does business planning facilitate the development of new ventures? Strategic Management Journal, v.24, p.1165-1185, 2003.

FISCHMANN, Adalberto Américo; ALMEIDA, Martinho Isnard Ribeiro de. Planejamento estratégico na prática. 2.ed. São Paulo: Atlas, 1991.

HAETINGER, Marc Henri. Benefícios do pilates. [out. 2008]. Disponível em: <http://www.hpilates.com >Acesso em: 25 fev. 2009.

HASELHOFF, Frits. Novo paradigma para o estudo das metas organizacionais. In: ANSOFF, Igor H.; DECLERCK, Roger P.; HAYES, Robert L. Do planejamento estratégico à administração estratégica. São Paulo: Atlas, 1990. 271 p. parte 1, p.28-40.

KISFALVI, Veronika. The entrepreneur's character, life issues, and strategy making. A field study. Journal of Business Venturing, v.17, p.489-518, 2002.

MINTZBERG, Henry. Ascensão e queda do planejamento estratégico. Porto Alegre: Bookman, 2004.

Bookman, 2000.

; AHLSTRAND, B.; LAMPEL, J. Safári da estratégia. Porto Alegre:

MÜLLER, C. J. Modelos de gestão integrando planejamento estratégico, sistemas de avaliação de desempenho e gerenciamento de processos (MEIO Modelo de Estratégia, Indicadores e Operações). 2003. Tese (Doutorado em Engenharia) - Universidade Federal do Rio Grande do Sul. Porto Alegre, 2003.

OLIVEIRA, Djalma de Pinto Rebouças de. Estratégia empresarial: uma abordagem empreendedora. 2.ed. São Paulo: Atlas, 1991.

Planejamento estratégico: conceitos, metodologia e prática. 24.ed. São

Paulo: Atlas, 2007. 
PIOVEZAN, Luís H.; LAURINDO, Fernando J. B.; CARVALHO, Marly M. de. Proposta de método para a formulação de estratégia em pequenas e médias empresas. Revista Produção Online, v.8, n.2, jul. 2008.

PORTER, Michael E. Estratégia competitiva: técnicas para a análise de indústrias e da concorrência. Rio de Janeiro: Elsevier, 2004.

What is Strategy? Harvard Business Review, Boston, v.74, n.6, p.61-78, Nov./Dec. 1996.

RASMUSSEN, U. W. Manual da metodologia do planejamento estratégico. São Paulo: Aduaneiras, 1990.

ROCHA, Marcelo. Microempresas no Brasil: análise do período de 1984 a 2005. Revista Eletrônica de Administração, Porto Alegre, ed.14, v.60, n.2, maio/ago. 2008.

ROSSI, Carlos A. V.; LUCE, Fernando B. Construção e proposição de um modelo de Planejamento Estratégico baseado em 10 anos de experiência. In: ENCONTRO ANUAL DA ANPAD, 26. 2002, Salvador. Anais... Salvador: ANPAD, 2002. 1 CD.

SANTOS, José Roberto Leite dos. Planejamento Estratégico: uma ferramenta acessível à microempresa. In: ENCONTRO NACIONAL DE ENGENHARIA DE PRODUÇÃO, 25. Porto Alegre, 2005. Anais... Porto Alegre: ABEPRO, 2005.

SANTOS, Leonardo Lemos da Silveira; ALVES, Ricardo César; ALMEIDA, Kenneth Nunes Tavares de. Formação de estratégias nas micro e pequenas empresas: um estudo no Centro-Oeste mineiro. Revista de Administração de Empresas, v.47, n.4, p.59-73, il. color, 2007.

SCRAMIM, Fernando Cezar Leandro; BATALHA, Mário Otávio. Planejamento Estratégico em pequena indústria: metodologia, aplicação e resultados. In: ENCONTRO NACIONAL DE ENGENHARIA DE PRODUÇÃO, 18, Gramado, 1997. Anais... Gramado: ABEPRO, 1997.

SERVIÇO BRASILEIRO DE APOIO ÀS MICRO E PEQUENAS EMPRESAS. Fatores condicionantes e taxas de sobrevicência e mortalidade das micro e pequenas empresas no Brasil. 2007. Disponível em: <http://www.biblioteca.sebrae.com.br/bds/BDS.nsf/ 8F5BDE79736CB 99483257447006CBAD3/\$File/NT00037936.pdf>. Acesso em: 18 mar. 2009.

SILVA, Edna Lúcia da; MENEZES, Estera Muszkat. Metodologia da pesquisa e elaboração de dissertação. 3.ed. Florianópolis: Laboratório de Ensino a Distância da UFSC, 2001.

SLACK, Nigel; CHAMBERS, Stuart; JOHNSTON, Robert. Administração da Produção. 2.ed. São Paulo: Atlas, 2002. 
TERENCE, Ana Cláudia Fernandes. Planejamento estratégico como ferramenta de competitividade na pequena empresa: desenvolvimento e avaliação de um roteiro prático para o processo de elaboração do planejamento. 2002. Dissertação (Mestrado em Engenharia de Produção) - Universidade de São Paulo. São Carlos, 2002.

THOMPSON Jr., Arthur A.; STRICKLAND III, A. J. Planejamento estratégico: elaboração, implementação e execução. São Paulo: Pioneira, 2000.

VASCONCELLOS FILHO, Paulo de; PAGNONCELLI, Dernizo. Construindo estratégias para vencer! 10.ed. Rio de Janeiro: Campus, 2001.

WRIGHT, Peter; KROLL, Mark J.; PARNELL, John. Administração estratégica: conceitos. São Paulo: Atlas, 2000.

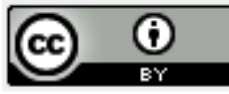

Artigo recebido em 26/06/2010 e aceito para publicação em 28/03/2012. 